\title{
Learning in agriculture: Building social capital in island communities
}

Sue Kilpatrick and Ian Falk

Associate Director and Director

Centre for Research and Learning in Regional Australia

University of Tasmania

Locked Bag 1-313

Launceston 7250,

Australia

Telephone: $+61(0) 363243142$

Fax: +61 (0)3 63243040

Email: Sue.Kilpatrick@utas.edu.au 



\title{
Learning in agriculture: Building social capital in island communities
}

\author{
Abstract \\ Social capital helps communities respond positively to change. Research in agricultural \\ businesses and into managing change through learning in communities, has highlighted the \\ importance of relationships between people and the formal and informal infrastructure of \\ communities to the quality of outcomes experienced by communities, businesses and \\ individuals. Communities can be geographic communities - the data drawn on in this paper is \\ from an island community, for example - or communities-of-common-purpose, such as \\ agricultural organisations. In this paper we review research into managing change through \\ learning and social capital, present a model of the simultaneous building and use of social \\ capital and explore the ways in which learning as part of an agricultural community can be \\ used to bring benefits to geographic communities such as islands.
}

The model presented in this paper stems from studies of the informal learning process that builds resilient communities. It conceptualises the way in which social capital is used and built in interactions between individuals. There are two stages to the model. The first stage depicts social capital at the micro level of one-on-one interactions where it is built and used. The second stage of the model is about the interrelationship of micro level social capital processes with the community and societal level social capital resources.

\section{Managing change through learning}

The power of social capital to improve outcomes for individuals, communities, regions and nations in the developing and developed wo rld has attracted considerable interest in recent times. Social capital is most simply defined as the norms and networks that enable people to act collectively (Woolcock \& Narayan, 2000). It is a set of resources that resides in the relationships among people and allows them to share their knowledge and skills, or human capital. Research into managing change through learning in communities and agricultural businesses, has highlighted the importance of relationships between people and the formal and informal infrastructure of communities to the quality of outcomes experienced by communities, businesses and individuals.

Island communities provide an ideal setting for the study of social capital. Their interactional infrastructure is readily isolated for study. 'Bridging ties' or networks that extend beyond the boundaries of communities, are more easily delineated in the case of an island community from 'bonding ties' (Gittell \& Vidal, 1998), which are those that operate within the community. In the case of other geographic communities or communities -of-commonpurpose, these ties are more difficult to delineate because community boundaries are less clear and less well identified in the data by interviewees, which is the case in the research discussed in this paper. The model of social capital forwarded in this paper was developed on an island from research data collected on that same island, Tasmania, Australia. The island experience has therefore enabled the authors to focus on the distinction between bonding and bridging ties or networks. These links have the power to influence whether communities survive and thrive in a rapidly changing global economy.

Rural communities are heavily reliant on agriculture. They have had to adjust as agriculture has been increasingly mechanised and commodity prices have been in long -term decline. In 
recent years, the ability to manage and respond to social, economic and environmental pressures has depended on the capacity of people and communities in rural and regional areas - on "the ability, organisation, attitudes, skills and resources that communities have to improve their economic and social situation" (Cavaye, 1999, p. 1).

For farmers, adjustment means adopting new practices, not only technical, but new ways of managing finances, natural resources and markets. This highlights the role of learning in rural adjustment and development. In Australia, agricultural organisations and government have recognised the benefits of providing effective learning opportunities for farmer s by developing a learning and training culture and subsidies for learning management skills, including rural leadership training (National Farmers' Federation, 1993). Learning by farmers to manage change in their own farm businesses can be expected to ben efit those businesses, but to what extent, if any, are there 'spin offs' for the wider rural community, including the other farm businesses that make up the industry?

Learning assists people to receive, decode and understand information, and hence make $b$ etter decisions. Learning can also make businesses aware of a greater range of possible new practices. In short, learning assists businesses to make successful changes to their practice (Kilpatrick, 2000).

A constructivist view of learning holds that exp loring others' values and attitudes assists in changing one's own values and attitudes (Kilpatrick, Bell \& Falk, 1999). Most management changes in farm businesses make use of several learning sources. Experts and other farmers, and training activities are frequently used as learning sources for change, and more than one member of the farm management team is involved in almost all of the learning -for-change processes (Kilpatrick et al., 1999). Learning that takes place in groups or communities plays an important role in modifying farmers' values by increasing their otherwise limited opportunities for interactive learning. The opportunity to alter values and attitudes in these ways increases the probability of a change to practice (Kilpatrick, 2000). Participa tion in organised education and training assists in the establishment of learning and support networks which are crucial in implementing change. In short, agriculture does not take place in a social or cultural vacuum. It is a social activity.

Networking among organisations, processors and farmer participants in a dairy supply chain in New Zealand facilitated the construction of knowledge by all those in the chain. The network's operation was facilitated by a 'place' to interact, for example a discussion group or a demonstration farm (Paine et al., 2000). Rural development in the United States is fostered by organisations which serve as networks for information exchange and facilitate cooperation among producers, processors, transporters and marketers (Ga lston \& Baehler, 1995). Mills and Winter (in Cerf et al., 2001) compare two institutional frameworks in British agriculture and show the greater effectiveness of locally-based, decentralised networked institutions with local involvement.

Farmers' use of multiple sources of information and support when making changes to their practices highlights the role of a diversity of networks and the quality of information and support they provide to farmers. Networks are social capital resources that are drawn upon in learning to manage change. The isolation experienced by many living and working in island communities, reduces the opportunity to build information and support networks. The New Zealand and British examples illustrate the role of the interactional infra structure in the learning process. The interactional infrastructure can facilitate not only use of social capital 
resources, but also the building of social capital resources. We return to the discussion of how social capital is built and used in agricultu re and rural communities after reviewing research related to social capital.

\section{Social capital}

There is a rapidly expanding body of research into social capital, which examines outcomes for families, communities, regions and nations. This research commonly at tempts to establish a link between the quality of the outcomes and the networks and norms that can be observed within the family, community, region or nation being studied. Examples include Putnam's (1993) study of regions in Italy and Narayan and Pritchet t's (1996) study of families in rural Africa. These studies have informed attempts at theoretical synthesis of how social capital works at family, community, regional and national levels and efforts to define just what it is, such as Woolcock (1998). It is clear from this work that networks and norms that allow people to act collectively are significant components of social capital. Community social infrastructure, in particular organisation structures, rules and procedures, opportunities for meeting, and human infrastructure, influences the effectiveness and efficiency of networks and associated norms.

Communities with moderate to high levels of social infrastructure (or social networks) are more likely to have successful locally initiated economic develo pment projects than those without. Social infrastructure or networks that are inclusive of people from diverse groups and backgrounds within the community (Flora, 1998), and that extend beyond the boundaries of the community, add to the capacity of a commu nity by increasing the range of knowledge, skills and expertise available to it. Social capital evolves in groups coming together to manage natural resources. Mature groups use external networks to achieve higher level aims (Pretty \& Ward, 2001). Local partnerships have the capacity to speak on behalf of the community to influence policies at higher levels, thus providing access to vertical external networks or linking ties. Dense bonding ties, or horizontal, internal networks, combined with the absence of bridging ties (external links) tend to have a negative effect on social capability, and are associated with ghettos and gangs (Knack \& Keefer, 1997). This is the 'dark side' of social capital referred to by Putnam (2000).

Norms, unwritten rules of behavi our that obviate the need for formal rules and sanctions and help to predict the behaviour of others, were identified by Putnam (1993) as a central part of social capital. We have already noted that a change to behaviour can only occur after values and attitudes have been tested and changed through learning interactions that help shape attitudes, values and norms, and can play a major role in the process of sharing attitudes, values and norms. Norms and values that accept diversity and include some shared $\mathrm{n}$ orms and values allow for inclusiveness and indicate willingness to entertain new ideas and to accept change (Flora, Flora \& Wade, 1996).

An expectation within a community of regular, honest and cooperative behaviour based on commonly shared norms develops trust (Fukuyama, 1995). Trust has a significant positive impact on economic activity, largely attributable to lower transactions costs (Knack \& Keefer, 1997). The development of trust among the members of a group or community has been identified as a prerequisite for commitment and action on behalf of the community (Kilpatrick, Bell \& Falk, 1999). Identification with the collective fosters a commitment to the collective and a willingness to act for its benefit. Identification and commitment are built ove $r$ time. 
A community that is able to develop a shared vision of its future, and how it could achieve this vision, shows a capability to manage change (Bandura, 1997). Those visions and future directions that are more successful will take into account the $\mathrm{h}$ istory of the community. Communities with a shared vision that has chronological continuity and community connection are able to achieve superior outcomes (Falk, Golding \& Balatti, 2000).

Interactions between network members are more effective if there a re commonly understood procedures, rules or precedents to guide interaction. Skills such as communication, organisation, decision-making, problem-solving and conflict resolution are part of a community's capacity to work together (Geddes, 1998). The capaci ty of social groups to act in their collective interest depends on the quality of the formal institutions under which they operate (Woolcock \& Narayan, 2000). Formal rules that constrain government and others in positions of power from acting arbitrarily f oster trust and cooperative norms (Knack \& Keefer, 1997). Communication sites assist in developing shared norms, values, visions and a community identity. Effective community leadership represents the interests of all stakeholders, encouraging them to work together to achieve the shared vision and strategic directions of the community; it is thus very different from corporate leadership which depends on "vertical lines of power and control" (Garlick, 1999).

Individuals or organisations can act as focal po ints for interaction between community and external organisations. These brokers 'speak the language' and understand the norms and values of the community as well as the norms and values of external organisations and are conduits into a community for new i deas. Industry and public organisations, including local government, and educational institutions can perform a brokerage role (Falk, 2000). In Australia, brokers negotiated with training providers to meet identified farmer training needs and linked Landcare groups to networks, and to funding agencies (Curtis \& Van Nouhuys, 1999). In the Andes, community sustainability stemmed from the brokerage role of new residents who had networks to access financial and technological resources and markets (Bebbington, 1999). The importance of continuity of staff and programs in rural communities is noted by Geddes (1998) in Europe and CRLRA (2000) in Australia. Programs should build on the physical and human infrastructure already present in communities (including netw orks and skills), and take account of the history of the community when setting future directions.

This review indicates that the elements of social capital that can be used to improve outcomes for individuals and communities are networks (internal and e xternal to the community), appropriate norms that generate trust, shared visions, appropriate organisational structures, rules and procedures and human infrastructure (self -confidence, leadership and social brokers). Social capital is built as norms and va lues are compared and shared, and trust developed. Participation in interactions and activities with community members has the potential to develop shared values and trust. Interaction can also develop individuals' self confidence, leadership capabilities and shared visions. Networks are formed and maintained through interaction. The effectiveness of interactions will be shaped by the context in which they take place, including the interactional infrastructure.

\section{CRLRA model of social capital building and upt ake}

We now explain the Centre for Research and Learning in Regional Australia (CRLRA) social capital model, which has been derived from extensive research (Falk \& Kilpatrick, 2000). There are two stages to the model. The first stage depicts social capital at the micro level of one-on-one interactions where it is built and used. The second stage is about the 
interrelationship of micro level social capital processes with the community and societal level social capital resources.

\section{Stage 1: Interactions between individuals build and use social capital}

Networks, norms and other elements of social capital are operationalised in interactions between people. Attempts to measure social capital have generally been at two levels: community and individual. The two are ne cessarily interrelated, demanding examination of the micro level of interactions between individuals within a community. CRLRA has examined the learning processes that build and use social capital in interactions in agriculture (Kilpatrick \& Bell, 1998; Kilpatrick, Bell \& Falk, 1999), and rural communities more generally (Falk \& Kilpatrick, 2000).

The first stage to the CRLRA social capital model depicts social capital at the micro level of one-on-one interactions where it is built and used (Figure 1).

\section{Figure 1 about here}

The social capital resources used in interpersonal, one -on-one interactions are (1) a knowledge of who, when and where to go for advice or resources and knowledge of how to get things done, called knowledge resources, and (2) identity resources, that is, being able and willing (committed) to act for the benefit of the community and its members. Knowledge resources relate to networks; knowing who to go to for information and how to get things done. Identity resources relate to norms; peo ple who share some values and visions being willing and able to act on behalf of others. Knowledge and identity resources allow community members to combine their skills and knowledge (human capital) with the knowledge and skills of others (Falk \& Kilpatri ck, 2000).

There are two sorts of positive outcomes possible from interactions that use social capital, one is some action or co-operation for the benefit of the community or its members, the other is the building or strengthening of knowledge and identi ty resources. Informal or deliberately arranged interactions help people get to know each other, and develop networks. The interactions also increase people's confidence to act for the benefit of the community and its members, develop shared values and bui ld a commitment to members of the community and the community as a whole. Thus social capital is dynamic, and is simultaneously used and built through learning processes.

Not all interactions have positive or beneficial outcomes for all individuals or com munities, neither do all interactions build social capital. The quality of the action outcome and the quality of the social capital resources that are built depend on the social capital available and drawn on in interactions. We suggest that the quality of the knowledge and identity resources (micro level social capital), accessed in the interaction, and the quality of the community and societal level social capital determines the quality of the outcomes, including the extent to which any others are disadvantaged.

Previous studies of the agricultural learning group Executive Link ${ }^{\mathrm{TM}}$ (Kilpatrick \& Bell, 1998; Kilpatrick, Bell \& Falk, 1999) found that getting to know each other and building trust were necessary before sensitive issues were introduced or discu ssed by group members. Changes in these sensitive areas were the changes that lead to major improvements in performance. Members had to get to know each other before they could regard each other as credible sources of advice and support; that is before the y would actually use each other's skills and 
knowledge. Getting to know each other is building knowledge resources. As people got to know each other, they developed a sense of belonging and commitment, and a sense that all group members could make valued c ontributions, that is, they built identity resources.

Participation in community activities provides opportunities for interaction, or opportunities for using social capital to enhance economic or social outcomes. The outcomes of interactions extended beyond outcomes for individuals and their businesses to building knowledge and identity resources. Shared language and experiences, trust, personal development and identification with the community are indicators of community social capital.

Knowledge and identity resources are drawn on or accessed in interactions between people. Therefore the availability and accessibility of opportunities for interaction in communities can be expected to influence the quality and outcomes of collaborative activity. The exte nt to which norms and values are shared, and the extent to which the community has an agreed direction or vision for the future will also contribute to the quality of outcomes.

We suggest that community-level social capital that is drawn on and added to in interactions is of two types: interactional infrastructure and values infrastructure. Interactional infrastructure provides networks that help identify people with whom to interact, sites and opportunities to come together to interact, and guides for th e interactions in the form of procedures and leadership. The second, values infrastructure, underlies all interactions; the degree of trust and sharing of norms, values and visions determines the ease with which community members interact.

\section{Stage 2: Community and societal level social capital}

The model's second stage, shown in Figure 2, shows the interrelationship of micro level social capital processes with community and societal level social capital resources. The interactional and values infrastructure a re social capital resources that can be observed at the community, or meso level and the societal, or macro, level.

\section{Figure 2 about here}

Individuals' knowledge and identity resources and community and societal social capital resources are interdependent. Interactions inevitably draw on the social capital of the community or organisation and society to which the interacting parties belong. The knowledge resources of a community include knowledge of: the skills, knowledge and affective attributes including values of others in the community; and the common physical resources of the community, formal and informal networks, procedures, rules and precedents, internal and external resources and sources of information (Falk \& Kilpatrick, 2000).

Identity resources (self-confidence, norms, values and vision) are shaped by the community and the wider society. The degree to which values, norms and visions are shared within the community will influence the actions arising from interpersonal interactions, and their outcomes.

The elements that make up the interactional and values infrastructure of communities and societies can be extracted from the literature reviewed earlier. Interactional infrastructure consists of relational networks (external and internal), proce dures, rules and organisational structures, communication sites, and human infrastructure, especially leadership and brokers. 
Values infrastructure consists of shared values, norms, attitudes and vision, inclusiveness, reciprocity, and identification with community.

The model built in Figures 1 and 2 applies to both geographic communities and communities of-common-purpose, such as island communities, and agricultural communities.

\section{Social capital and learning for agriculture}

The agricultural industry in island Tasmania is a community-of-common-purpose, with many sub-communities-of-common-purpose, for example local dairy groups. There are also communities-of-common-purpose, such as Landcare environmental working groups, that cross the boundary between agricult ure and the rest of the island community. All these communities can build and use social capital for the mutual benefit of community members.

Sustainable agricultural practices have been found to be highly compatible with collective action toward local community goals by Flora (1995). Flora studied two groups of agricultural communities in the United States, one having a predominance of farmers using 'sustainable' practices, the other a predominance of farmers using conventional practices. She concluded that local organisations, formed around the sustainable agriculture movement, together with a problem-solving mindset and the ability to learn and adapt to local conditions, help to build and nurture social capital.

Agriculture has a history of learning thr ough government extension services, which are a deliberate attempt to build bridging ties. The agricultural community is used to learning together and building social capital, though more often in terms of close -knit community bonding ties. On a small island such as Tasmania, this can be exaggerated and result in a agricultural 'culture' of resistance to change, since it is only through the bridging ties that act as two-way communication channels that new information is acquired and acted upon.

In recent years agriculture has experienced an increasing interest in learning, and participation in activities that are best described as training (Kilpatrick et al., 1999). Can this evolving learning culture in agriculture be used to build social capital for the b roader island community? These quotes from farmers interviewed for CRLRA projects show group learning activities can build social capital resources which have the potential to transfer beyond the agricultural community:

[The discussion group has] been going for about 10 years, my husband and one other community member are sort of the leaders of it and always have been and I think that's probably the reason why it's survived like it has because these two people have been driving it.

Not only is leadership seen as important, but also the bonding ties stemming from close associations. These ties gradually extended:

There's four couples get together every two or three months... we have gone chemical free with our wool. We have tried a number of revegetation projects that we are still working on... we run management decisions past each other... it makes you stop and think about your operation... there is too much reading for one person now so we all subscribe to different journals and we... pool our knowledge and it saves everybody a lot of extra reading...

This quote illustrates the consolidation and establishment of common values and their resulting bonding ties, networks, values and trust. From this consolidation stage, bridging ties allow and sustain the learning transfer to a broader community. The next quote suggests that 
social capital resources are built in agricultural communities, then transferred to the local community:

My role is probably important... I see mine as the personal relationship side, because havi ng been in partnership all my life, I know that it's pretty important to work on that part of it, and I see that as my chief role to make sure that everyone's getting on well together. I'm quite involved in community work.

Organisational structures established to meet the needs of agriculture, such as the Landcare movement and growers associations, can act as brokers, providing links into networks external to the community, including the sustainability of learning and transfer systems and funding:

Every district would have a Growers Association. They do a lot of community work to make sure that the industry is part of the community rather than just an isolated business group.

The quality of the partnership between community and government agency is crit ical to the Landcare program's success (Curtis \& Lockwood, 1998). Pretty and Frank (2000) urge that policies for natural resource management should support the development of human and social capital, and provide sufficient support to avoid burn -out of individuals. This suggests that building and maintenance of social capital resources in rural communities requires resourcing, from within the community or outside.

\section{Conclusion}

The capacity of a community-of-common-purpose has been seen as far greater than the sum of the individual capacities of its members. The 'bonding' and 'bridging' ties identified in the social capital literature enable sharing of skills, knowledge and resources within the group while at the same time accessing outside resources. Social ca pacity is greater where people are willing and able to work together for mutual benefit, which means they have sufficient confidence, appropriate norms and interpersonal skills such as conflict resolution (Falk \& Kilpatrick, 2000).

The CRLRA model of social capital presented here argues that the social capital resources that increase the capacity of a community are simultaneously built and drawn upon in learning interactions between individuals. At the micro level, these resources are knowledge and identity resources. Knowledge resources relate to networks; knowing who to go to for information and how to get things done. Identity resources relate to norms; people who share some values and visions being willing and able to act on behalf of others. Knowledge and identity resources are used and built in the context of the meso, community level social capital resources; the interactional and values infrastructures of the community, and the macro, societial interactional and values infrastructures.

Agriculture in island Tasmania has an established culture of learning together that is increasingly embracing learning in groups and more structured training. The CRLRA model of social capital has been partly developed from data showing how social capital is built an $\mathrm{d}$ used in structured and informal learning activities of island Tasmanian farmers. There is evidence that the social capital developed in the agricultural community has spins offs for rural communities more generally as these knowledge and identity resourc es and the interactional infrastructure of networks, institutions, social brokers and effective leadership skills built for agriculture are used for wider benefit. 
Social capital and learning have the potential to improve outcomes for communities by developing their capacity to manage change. Change is a process of groups learning in pursuit of common goals. Islands are unusually placed to capitalise on social capital. Distinctive identity resources are likely to be pronounced on islands which provide stra tegic advantages for economic consolidation and development, such as niche marketing of specialty produce and tourism. They have particular histories, events, geographies, issues and stories that can be used in the development of strategic socio-economic responses. The bonding ties that can form the bases of island communities' constructed identities are partly defined by the boundary of water that surrounds them. A shared history can be drawn on in crafting a shared vision that has chronological continuity.

The value-added nature of island identity has another benefit in that the networks of island interactional infrastructure are readily identified as either internal or external. Island communities face special challenges in developing external networks to the rest of their region and the world. This paper has shown that the balance of bonding and bridging ties in the agricultural learning community example has external networks and other social capital resources that can be used to benefit island communi ties. Close attention must be paid to the balance between the bonding and bridging ties, since an excess of bonding ties can result in over-insularity, while an excess of bridging ties can result in a homogenisation of distinctive socio-cultural features, undermining the impact on some industries (e.g., tourism).

\section{References}

Bandura, A. (1997) Self-efficacy in Changing Societies (Melbourne, Cambridge University Press).

Cavaye, J. (1999) The role of public agencies in helping rural communities build social capital, International Symposium of Society and Resource Management, July.

Cerf, M., Gibbon, D., Hubert, B., Ison, R., Jiggins, J., Paine, M., Proost, J. \& Roling, N. (2001) Cow up a Tree: knowing and learning for change in agriculture - case studies from industrialised countries (Versailles, France, INRA Editions Science Update).

CRLRA (2000) Managing Change through VET: the role of vocational education and training in regional Australia (Launceston, University of Tasmania). Available http://www.crlra.utas.edu.au

Curtis, A. \& Lockwood, M. (1998) Natural resource policy for rural Australia, in: J. Prately \& A. Robertson (Eds.) Agriculture and the Environmental Imperative (Collingwood, Victoria, CSIRO).

Curtis, A. \& Van Nouhuys, M. (1999) Landcare in Victoria: beyond on-ground work, Report no. 125 (Albury, Victoria, The Johnston Centre for Conservation and Restoration of Landscapes, Charles Sturt University).

Falk, I. (2000) The characteristic of the public provider: the role and function of TAFE Institutes in communities, Position paper for TAFE Directors Australia.

Falk, I., Balatti, J. \& Golding, B. (2001), Building Communities: ACE, lifelong learning and social capital (Melbourne, Adult, Community and Further Education Board). 
Falk, I. \& Kilpatrick, S. (2000) What is social capital? A study of interaction in a rural community, Sociologia Ruralis, 40(1), pp. 87-110.

Floden, R., Goertz M. \& O’Day, J. (1995) Capacity building in systemic reform, Phi Delta Kappa, 77(1), pp. 19-21.

Flora, C. (1995) Social capital and sustainability: agriculture and communities in the Great Plains and the Corn Belt, Research in rural sociology and development: A research annual, 6, pp. 227-246.

Flora, C., Flora, J. \& Wade, K. (1996) Measuring success and empowerment, in: N. Wa lzer (Ed.) Community Strategic Visioning Programs, (London, Praeger), pp. 57-74.

Flora, J., Sharp, J., Flora, C., \& Newlon, B. (1997) Entrepreneurial social infrastructure and locally initiated economic development in the non -metropolitan United States, Sociological Quarterly, 38(4), pp. 623-645.

Flora, J. (1998) Social capital and communities of place (Speech by Rural Sociological Society President Jan L. Flora), Rural Sociology, 63(4), pp. 481-483.

Fukuyama, F. (1995) Trust: the social virtues and the creation of prosperity (New York, Free Press).

Galston, W. \& Baehler, K. (1995) Rural Development in the United States: connecting theory, practice and possibilities (Washington D.C., Island Press).

Garlick, S. (1999) Research Basis for Regional Development Capacity building: a regional development policy for Western Australia, Appendix 2. Available:

http://www.regional.wa.gov/policy/html/capacity/

Geddes, M. (1998) Local Partnership: a successful strategy for social cohesion? (Dublin, Ireland, European Foundation for Improvement of Living and Working Conditions).

Gittell, R., \& Vidal, A. (1998) Community Organizing: Building Social Capital as a Development Strategy (Thousand Oaks, CA, SAGE Publications).

Kilpatrick, S. (2000) Education and training: Impacts on farm management practice, Journal of Agricultural Education and Extension, 7(2), pp. 105-116.

Kilpatrick, S. \& Bell, R. (1998) Support networks and trust: how social capital facilitates economic outcomes for small businesses, in: Learning Communities, R egional

Sustainability and the Learning Society: an international symposium (Launceston, Centre for Research and Learning in Regional Australia, University of Tasmania) pp. 223 -231.

Kilpatrick, S., Bell, R. \& Falk, I. (1999) The role of group learning in building social capital, Journal of Vocational Education and Training, 51(1), pp. 129-144.

Kilpatrick, S., Johns, S., Murray -Prior, R. \& Hart, D. (1999) Managing Farming: how farmers learn, RIRDC Publication No 99/31 (Canberra, Rural Industries Research an d Development Corporation).

Kilpatrick, S., Morgan, H., Falk, I. (1998) Change, visions and values and non -formal education, Australian Journal of Adult and Community Education, 38(1), pp. 3-8. 
Knack, S. \& Keefer, P. (1997) Does social capital have an econ omic payoff? A cross-country investigation, Quarterly Journal of Economics, 112, pp. 1251-1288.

Krishna, A. \& Uphoff, N. (1999) Mapping and measuring social capital: a conceptual and empirical study of collective action for conserving and developing waters heds in Rajassthan, India. Social Capital Initiative Working Paper No. 13 (Washington D.C., World Bank).

Narayan, D. \& Pritchett, L. (1996) Cents and Sociability: household income and social capital in rural Tanzania, World Bank Policy Research Paper.

http://www.worldbank.org/research/growth/absnapr.htm

National Farmers Federation (1993) New Horizons: a strategy for Australia's agrifood industries (Canberra, National Farmers Federation).

Paine, M., LeHeron, R., Penny, G \& Sheath G. (2000) From research on to research with: The learning challenges of the Learning Challenges project, World Congress on Action Research, Action Learning and Participatory Action Research . http://www.ballarat.edu.au/alarpm/docs/Paine.MS-FullPaper

Pretty, J. \& Frank, B. (2000) Participation and social capital formation in natural resource management: achievements and lessons, International Landcare Conference, Melbourne. http://www.affa.gov.au/agfor/landcare/pub/dof1 -eval/references.html

Pretty, J. \& Ward, H. (2001) Social capital and the environment, World Development, 29(2), pp. 209-227.

Putnam, R. (1993) Making Democracy Work: civic traditions in modern Italy (Princeton, Princeton University Press).

Putnam, R. (2000) Bowling Alone: the collapse and revival of American community (New York, Simon and Schuster).

Woolcock, M. (1998) Social capital and economic development: tow ard a theoretical synthesis and policy framework, Theory and Society, 27, pp. 151-208.

Woolcock, M. \& Narayan, D, (2000) Social capital: implications for development theory, research and policy, World Bank Research Observer, 15(1), pp. 225-249. 
Figure 1: Simultaneous building and using of social capital in interactions between individuals

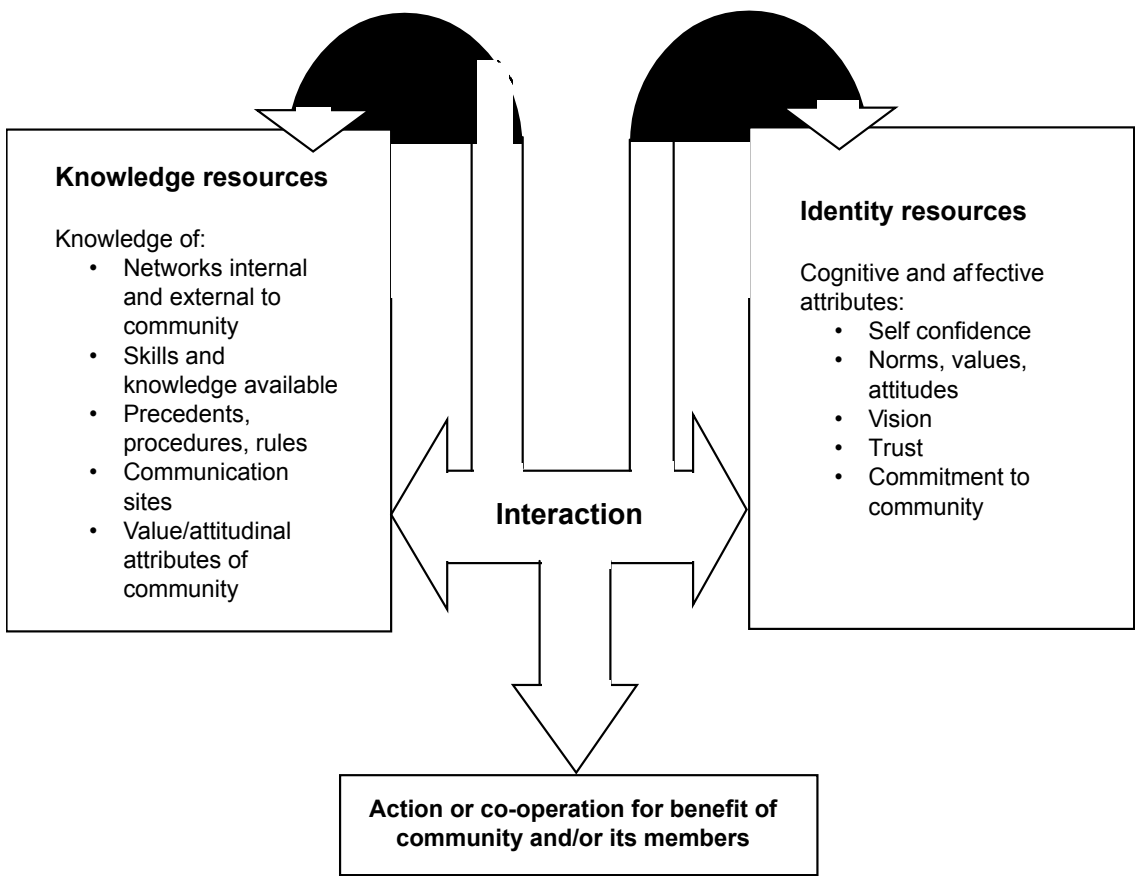


Figure 2: Societal and community level social capital resources sustained by interpersonal interactions

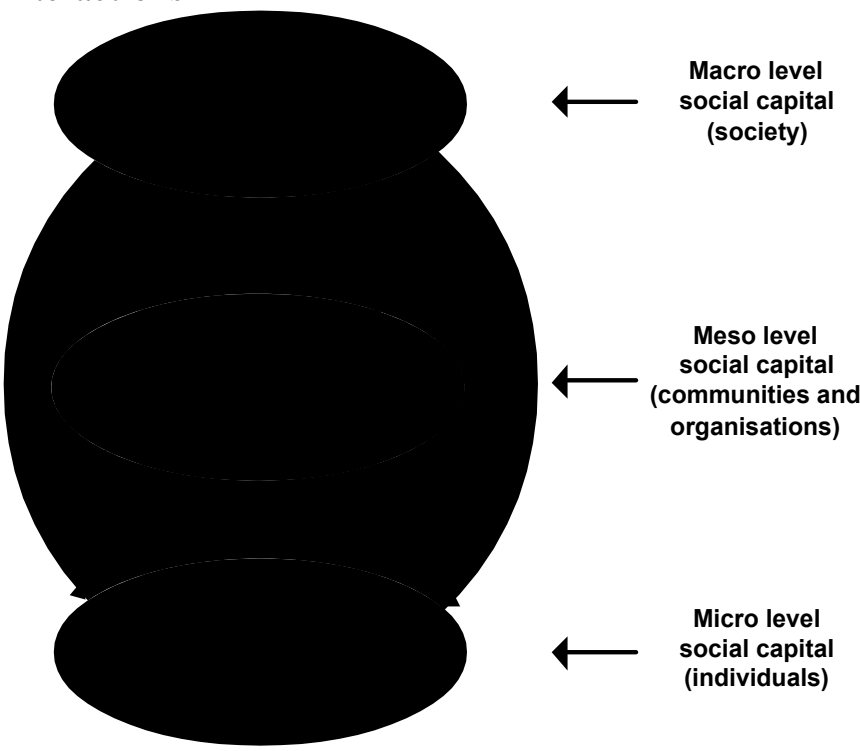

